\title{
ELEMENTOS MÍTICOS Y PARADIGMAS CIENTÍFICOS. ACERCAMIENTO CRÍTICO AL MECANICISMO DE NEWTON, AL DARWINISMO Y A LA FÍSICA ASTRONÓMICA
}

\author{
Mythical Elements and Scientific Paradigms. Critical Approximation to \\ the Mechanism of Newton, Darwinism and Astronomical Physics
}

\author{
Julio López Saco \\ julosa.ucv@gmail.com \\ Universidad Central de Venezuela. Venezuela
}

Fecha de recepción: 11/07/2018

Fecha de aceptación: 19/12/2018

\begin{abstract}
RESUMEN: La consideración mítica, como la científica, es una manera posible de interpretar la experiencia. Cada una de ellas posee sus contenidos categóricos, principios apriorísticos yestipulaciones. El estatus paradigmático de la ciencia depende de una estructura narrativa, propia del mito, a través de la cual las investigaciones empírico-analíticas buscan persuadir. La ciencia incluye lo "mítico» en su exposición pública, mostrándose parasitaria sobre el potencial interpretativo del mito, su durabilidad y persistencia. Lo «mítico» y lo «científico» se unen, así, en la «estética» del entendimiento humano. El mito participa como una suerte de ciencia de lo abstracto que llega a ser concreto, un lenguaje simbólico usado para designar significados dentro de lo cotidiano. El conocimiento científico ni es universal ni absoluto, sino limitado y provisional. A causa de que la inducción no puede traducirse en leyes generales, y de que el conocimiento científico es un producto de las estructuras interpretativas humanas, que son, ellas mismas, variables, relativas y creativamente empleadas (desde la imaginación mítico-simbólica), las verdades de la ciencia no pueden ser inequívocamente objetivas. En este trabajo se harán, en tal sentido, unas valoraciones referidas al mecanicismo de Newton, al Darwinismo y a la Física astronómica.
\end{abstract}

Palabras clave: mito; historia; ciencia; paradigmas.

ABSTRACT: The mythical account, as the scientist, is a possible way of interpreting experience. Each of them has its categorical content, aprioristic principles and provisions. The paradigmatic 
status of science depends on a structure, narrative of the myth, through which empirical-analytical investigations seek to persuade. Science includes the "mythical» in his public exposure, being parasitic on the interpretive potential of the myth, its durability and persistence. The "mythical» and "scientific» combine, "aesthetics» of human understanding. The myth is involved as a sort of science of abstraction that becomes concrete, a symbolic language used to designate meanings within everyday life. Scientific knowledge is neither universal nor absolute, but limited and provisional. Because the induction may not be translated into general laws, and that scientific knowledge is a product of human interpretive structures, which they themselves, variables, are, relating and creatively employed (from the mythical-symbolic imagination), the truths of science cannot be unambiguously objective. This work will be made, in this regard, some estimates referred to the mechanism of Newton, Darwinism and astronomical physics.

Keywords: myth; history; science; paradigms.

SUMARIO: 1. Introducción. 2. Entre las ciencias y el mito. Variables del proceder científico. 3. Newton, Darwin y el Universo. 4. Conclusión. 5. Referencias bibliográficas.

\section{INTRODUCCIÓN}

Cuando el ser humano piensa o actúa, por mediación de las categorías racionales, o se comporta míticamente, está sumergido en la intersubjetividad y comparte, complementariamente, concepto e imágenes, en un mundo sacro y profano. Las ciencias, en concreto las que aquí se analizan, y el mito ofrecen, de este modo, "teorías» no medibles entre sí, sobre el mundo y la realidad en conjunto, lo que supone que son formas de pensamiento que «razonan» desde diferentes perspectivas, sobre las diversas facetas de lo real. Como ofrecen información válida, aunque variada, sobre lo mismo, ambos se conforman como estructuras ontológicas de los objetos de experiencia, ninguna mejor que la otra, sino complementarias.

Una información válida, entendemos, en el sentido de su eficacia y de que produzca algún efecto, sobre presupuestos semejantes. Ninguna por encima de la otra, diríamos, en sus respectivos contextos, y en un sentido práctico y moral, si bien dependiendo del interés o de la finalidad buscada la información de una u otra puede ser considerada mejor o peor. En tal sentido, ninguna interpretación de la realidad, mítica, histórica, filosófica, científica, posee una validez incondicional, sino que deben compartir méritos en función de las multipolaridades de aquella y del hombre.

El ser humano quiere, no se olvide, dar sentido a la existencia, y para ello debe recurrir, en función de los diversos aspectos de la verdad, a los frentes del mito y el logos, sin imposiciones reduccionistas. Una específica visión cientista y positivista del mundo (ciertamente no la única) es incompleta sin la fuerza de las imágenes míticas del hombre.

Hoy en día ya es una asunción común el hecho de que no se puede eliminar del discurso científico el componente figurativo, así como el que los mitos incorporan 
ciertas formas explicativas de la realidad ${ }^{1}$. Muchas prácticas, digamos chamánicas o de hechicería, por ejemplo, se fundamentan en observaciones empíricas minuciosas, y son capaces de predecir, con acierto, el modo de comportarse la naturaleza. Dichas observaciones no se insertan en un corpus teórico genérico porque son patrimonio de otras tradiciones culturales. Así, ciertas actividades científicas reposan sobre creencias metafísicas: la idea, la creencia de que la natura sigue un curso regular, no arbitrario, el principio de que todo efecto tiene una causa, o la inducción; esto es, el principio de uniformidad de la naturaleza. Tales principios son, en realidad, condiciones de posibilidad de la experiencia.

\section{ENTRE LAS CIENCIAS Y EL MITO. VARIABLES DEL PROCEDER CIENTÍFICO}

El principio de uniformidad de la naturaleza se vincula con la creencia en la causalidad (el universo está gobernado por leyes regulares, determinables e incambiables), si bien algunos piensan que hay relaciones causales que no están regidas por leyes (la explosión generadora del Universo o los estados mentales humanos que provocan nuestro accionar). En definitiva, la ciencia posee presupuestos y fundamentos no científicos ${ }^{2}$. La ciencia, como el mito, debe ser considerada como una red de creencias que configura una totalidad. A partir de una concepción atomista del significado, no se podría decir, en consecuencia, que este no tiene un sentido.

Desde una configuración abstracta, el texto de matemática o de lógica necesita proyectar una historia concreta, con empleo de metáforas explicativas o a base de ejemplos del mundo real, que permita ayudarnos a intuir y visualizar; desde una historia concreta, por el contrario, el mito ayuda a que ascendamos hacia una configuración abstracta. En los dos casos, las imágenes son modelos, y en los dos se quiere mostrar algo que se encuentra más allá. Tal relación (modelos científicomatemáticos y situaciones míticas) se puede ver en lo que los propios científicos argumentan sobre la vida y sus posibilidades ${ }^{3}$. Así pues, en cualquier cultura, las ideas acerca de la forma del mundo, el sentido y origen de la vida o la historia, determinan estructuras abstractas. Es el caso del espacio, el tiempo o las formas de clasificación.

Las nociones científicas mantienen, así mismo, incorporadas ciertas fantasías, imágenes (ni objetivas ni antisépticas), ideologías, semi creencias, esperanzas,

${ }^{1}$ Véase Hesse \& Arbib, M.A., 1987, esp. pp. 12-15 y 24, y Chaparro \& Schumacher, 2003, esp. pp. 14-15, 66-69 y 77. Acerca de la discusión de los paradigmas científicos, en concreto de aquellos de las ramas que aquí tratamos, véase por ejemplo, Abdalla, 2010, esp. pp. 19-20 y ss.

${ }^{2}$ Es hora, en consecuencia, de superar el monismo metodológico por el pluralismo de métodos, que no identifica ciencia con conocimiento total. Es decir, que el conocimiento es más que la ciencia.

${ }^{3}$ Véase Páramo, 1989, pp. 27-67; 1997, pp. 25-32. 
temores, orgullos y vanidades. El aparente éxito de la ciencia se basa, en esencia, en un proceso de reducción, en tratar solamente aquello que cree poder resolver, en destacar lo que se considera relevante, y en simplificar lo más posible, enfatizando la verdad literal, en especial en las ciencias físicas ${ }^{4}$. Un ejemplo común sería la idea de materia, que no es exclusivamente mecanicista. Se ha hecho, desde la óptica científica, entendida como una nueva ideología, imperativa la superioridad de la forma sobre la sustancia, la precisión sobre la integridad, el método sobre la actividad.

La ciencia ha tenido primacía porque se entiende que su conocimiento ni es falso ni ilusorio y, además, tampoco es superficial o provisional. Revela realidad, mientras que las experiencias subjetivas, apariencias. Ahora bien, el conocimiento científico no es inmutable, y pueden existir hechos objetivos sobre experiencias subjetivas, además de que algunas apariencias, como las penas o los problemas mentales, pueden ser elementos destacados de los hechos que nos afectan.

Por otra parte, los grandes avances científicos, como los trabajos en ingeniería genética, particularmente la algenia (las especies vivas somos estados de un continuum, de forma, que, eventualmente, podemos intercambiar nuestras propiedades), implican un poderoso acto de fe, así como la aceptación de un probable destino humano que está ya presente en nuestra biología, pero cuyo control no podemos asegurar. Los conceptos que usamos en la vida cotidiana suelen ser, a menudo, ambivalentes, en respuesta a la complejidad de la vida humana, que no puede ser solamente descrita. Es lo que ocurre con términos como confianza, consentimiento y esmero, o ciertas nociones de la biología, como selección natural, adaptación y evolución (vid infra). La tendencia científica a la claridad y la simplificación puede limitar los contenidos y los sentidos de las cosas. Además, se suele pensar que las explicaciones mecanicistas son siempre más científicas que los conceptos referidos a los contextos específicamente humanos. La única forma autorizada de explicación, la elección deliberada, suele dejar al margen cualquier tendencia instintiva 5 . Biológicamente hablando, no obstante, ambos tipos de explicación no tienen por qué oponerse.

${ }^{4}$ La visión atomístico-reductiva de la explicación de las cosas sugiere que el modo correcto de entender las complejidades globales es fragmentarlas en secciones más pequeñas, y manejables, con lo que se pierden algunos aspectos en el camino. Tal visión propone, por ejemplo, soluciones bioquímicas a ciertos problemas e inconvenientes sociales y psicológicos. En definitiva, la tecnología forma nuestro simbolismo y nuestra visión de lo real. Véase Waddington, 1941, pp. 168-171, y Midgley, 2011, esp. pp. XIV-XV de la Introducción, 3 y 44.

${ }^{5}$ Algunas conductas innatas pueden evocar, incluso en los animales, intenciones conscientes. Véase Midgley, 2011, esp. pp. 203-203; Stock, 2002, esp. pp. 44-48 y ss.; y Griffin, 1984, p. 116: «It is always dangerous for biologists to asume that only on of two or more types of explanation must apply universally». 
La ciencia, además, es un producto social e histórico, obra de personas, la comunidad científica, que comparten valores y prejuicios, entre ellos políticos, religiosos e ideológicos. Gustos y prejuicios, así como obsesiones y particulares cosmovisiones, pueden ser condicionantes de la labor de investigación de los científicos, impidiéndoles observar algunos fenómenos y, sobre todo, haciéndoles ver otros que parecen no corresponder a la «realidad». Así, las preferencias mítico-religiosas y estéticas de Copérnico son las que le impulsaron a formular que era el Sol, y no la Tierra, la que debería encontrase en el centro del Universo. El ambiente cultural anti racionalista y anticausalista de la República de Weimar fue la que posibilitó una física cuántica negadora de principios científicos considerados axiomáticos, como el principio de identidad o la capacidad de exacta predicción ${ }^{6}$. En ocasiones, los criterios estéticos ayudan a formular teorías científicas o a rechazarlas. Ello supone el empleo de imágenes, implícitas o no, por parte de los científicos. En tal sentido, por ejemplo, se confió en que la teoría de la relatividad tenía que ser cierta en virtud de su elegancia.

El mito, como la ciencia, es un lenguaje y una manera de pensamiento que busca, también como la ciencia, hacer entendibles las cosas que existen y cómo estas son, de modo que se puede entender como un despliegue hacia lo conceptual que busca representar los orígenes y las transformaciones que acontecen en el mundo, mostrando realidades bajo su propia seudo realidad.

La ciencia, al menos después de Kant, no puede establecer verdades absolutas y objetivas, debido a que ella misma es producto de estructuras mentales en sí mismas relativas, además de que su método de observación es la que produce la realidad objetiva que trata de explicar. En este sentido, el conocimiento humano, del tipo que sea, es interpretación, sin que ninguna sea definitiva y total ${ }^{7}$. Si bien la mentalidad occidental moderna es aún dualista, de acuerdo al modelo racional ilustrado, también goza de una participación con el mundo a través de la intuición y la imaginación. Ello significa que es reconciliable la observación empírica con la intuición espiritual.

Desde una perspectiva ontológica, la ciencia no puede, desde luego, garantizar fundamentos inquebrantables, salvo que se caiga en un eficiente dogmatismo. $\mathrm{Si}$ se pretende explicar la cosmovisión científica, se debe acudir a formas mítico-religiosas de la experiencia o hablar de "casualidades». El mito es también un sistema de experiencias (eso sí, numinosas, divinas, que no distinguen entre ideal y material, nombre y objeto o sujeto y objeto) y, a la par, un medio para las explicaciones y los órdenes sistemáticos (para ordenar sistemáticamente y explicar). El puesto

${ }^{6}$ Véase Selleri, 1986, pp. 35-37 y ss.; Bermejo Barrera, 1994, esp. pp. 30-33; Gross, 1990, esp. pp. 21-22; Kuhn, 1979, esp. pp. 51 y ss.; y Maxwell, 1984, esp. pp. 56-59.

${ }^{7}$ Sobre este asunto debe verse Tarnas, 1991, esp. pp. 359-360 y 397-399; Harpur, 2010, esp. pp. 311, y Gellner, 1975, esp. pp. 205-207. 
específico de las explicaciones causales de la realidad es ocupado en el mito por una "reconducción aitiológica con una reivindicación final»; esto es, las historias de los orígenes ocupan el puesto de las fundamentaciones ${ }^{8}$.

La aparente superioridad de la ciencia respecto al mito puede entenderse como fáctica e histórica, y no se basa en una superioridad de racionalidad concluyente, pues lo mítico, como lo científico, es punto de partida de un pensamiento empírico y argumental, aunque aquel se centra en objetos distintos de los que la ciencia trata. Aunque solo sea formalmente, el modelo «explicativo» del mito corresponde sin desentonar con el científico, con enunciados históricos, sociológicos y psicológicos fundamentales, si bien el primero reconoce la explicación por mediación de las incidencias de seres numinosos. Las condiciones míticas del mito son correspondidas por las axiomáticas de la ciencia.

Las ciencias y la racionalidad suelen ya reconocer los límites a las explicaciones; en ese punto el mito, o algo análogo al significado mítico, puede servir para ofrecer una positiva apropiación expresiva de tales limitaciones, que el mito también posee pero que no le interesa objetar. Es lo que puede estar detrás de la posible inconmensurabilidad de los paradigmas científicos, el rol creativo en la búsqueda científica, y en la relevancia de los elementos estéticos, socio-políticos e históricos en la propia practicidad de la ciencia. En cualquier modo, ni a través de las corrientes racionalistas ni de las científicas, se puede hablar de progreso en relación al mito. Tal cuestionable presunción solo ha derivado de la asunción de exclusividad por parte de los filósofos.

Como sistema, las ciencias no dejan de ser la representación de la representación, en tanto que crea ficciones funcionales deductivamente demostradas y demostrables a partir de supuestos validados en el marco del carácter arbitrario de toda sistematización. El sistema, en el mito, es un residuo desgajado de la expresión de lo que es inexpresable. Ambos, ciencias y mito, son realidades propias dentro de ese espectro que denominamos aletheia ${ }^{9}$.

La ciencia se ha mantenido al margen de la problemática del lenguaje cotidiano y de su praxis, sin que pueda, ni siquiera, responder las interrogantes que la vida destila, perdiendo con ello patrones valorativos. Esto indica que la relación entre ciencia y capacidad vital parece haber se roto. Restablecer tal vínculo exige recordar y recuperar lo tradicional olvidado, dejando entrever un pensar figurativo y pluridimensional. Es decir, hay que recuperar la conexión íntima entre pensamiento

${ }^{8}$ Véase Hübner, 1984, esp. pp. 20-25; 1981, vol. 2, pp. 11-36; 1996, pp. 257-270 y ss. Algunos autores ponen en duda el paralelismo entre las experiencias científicas y míticas porque el método comprobatorio prescinde de todo contenido y entiende la conmensurabilidad como formal. Al respecto véase Kolakowski, Spaemann \& Löw, (Comps.), 1986, passim.

${ }^{9}$ La realidad de la ciencia y la razón, indiscutibles, depende, en cualquier caso, de entender que la realidad es una representación y, por ende, prácticamente una ilusión. Cf. Ayala Blanco, 2004, esp. pp. 22 y 27. Revísese también Hofstadter, 1979, passim. 
teórico y experiencia personal, pues lo puramente racional es incapaz de captar la plenitud del sentido.

La ciencia podría verse, por consiguiente, como un mito más que el mundo proyecta: las personas viven la ciencia como un mito, pues es contemplada como un conjunto de imágenes dadas por reales y percibidas como potencias casi sobrenaturales. El armazón científico reposa y se consolida sobre ciertas simulaciones o apariencias convencionales (las partículas subatómicas, el verdadero relato mítico del Big Bang o el átomo, una apariencia, eso sí, funcional, básica para comprender el Universo o la imagen que de él se tiene y que nadie pone en duda aunque no se haya visto). En tal sentido, las realidades de héroes o dioses, como de esos átomos, el estado, o el yo psicológico, son las mismas: realidades que trascienden al ser humano pero sin las que no sería posible la inmanencia. Entonces, se puede decir, que el mito es la vida misma (si explica algo lo hace porque es eso que explica), y una realidad creada y vitalmente sentida ${ }^{10}$.

La ciencia funciona como un sistema universal y generalmente válido, pero en su accionar hay un simbolismo. Fuera del mismo se encuentra en mundo de lo misterioso. Los hechos se relacionan entre sí, se conectan, pero es menester saber con qué imágenes y esquemas tales conexiones se establecen. Así pues, además del mundo formal, que pretende ser el único científico en verdad y real, existe un ámbito anterior a las conexiones lógicas, inexpresable y, naturalmente, científicamente inalcanzable $^{11}$. No nos engañemos entonces: hay dos saberes, uno racional, que solo puede captar y expresar lo general, difícilmente lo individual y concreto, y otro mítico-simbólico, metafísico, raíz en la que se fundamenta la realidad del individuo ${ }^{12}$.

En realidad, mito y ciencia están más cerca de lo que parece. Lo mítico puede convertirse en ciencia, como el creacionismo y su diseño inteligente, mientras que la ciencia (en este caso el evolucionismo para seguir con el mismo ejemplo), se encuentra teñido de aspectos mitificantes. Mientras en el primer caso se intenta conferirle sentido a la vida humana, en el segundo se pretende explicar el ámbito físico del hombre en el mundo. En cierto modo, ciencia y mito comparten la inferencia y la observación como mecanismos de expresión y metodológicos. Algunas teorías científicas permanecen como mitos, esto es, como teorías que, como los mitos, no pueden ser probadas, solamente desaprobadas, permaneciendo esencialmente inciertas e hipotéticas. Existen, lo advertía $\mathrm{K}$. Popper ${ }^{13}$, mitos científicos y religiosos,

${ }^{10}$ Véase Losev, 1998, pp. 15-18 y ss.

${ }^{11}$ Es una obligación en este punto revisar Wittgenstein, 1987, esp. pp.16-38 y ss. Véase también, Grassi , 2003, esp. pp. 11-13.

${ }^{12}$ Véase al respecto, Aristóteles, Tratados de Lógica (Órganon), 2 vols., edit. Gredos, Madrid, 1988, especialmente, en el vol. II, 72a 25-72a 27 y ss., 72a 37 y ss.

${ }^{13}$ Popper, 1974 , pp. 126-127 y ss. Véase también, Rodin, 1957, esp. pp. 382-384, y Segal, 2004, p. 34. 
ambos dogmáticos en un momento dado, aunque los primeros suelen someterse a cuestionamiento. Por otro lado, muchos han sido los intentos de reinterpretar científicamente mitos, como el episodio del arca de Noé o de las plagas de Egipto, convirtiéndose casi en propuestas científicas indiscutibles y casi paradigmáticas.

Al igual que el mito narra gestas, la ciencia relata historias, cuentos dichos de múltiples maneras, a veces contraponiéndose, pero siempre entrelazados en imágenes. En tal sentido, las partículas elementales y la naturaleza de dioses y héroes es la misma; esto, es, imágenes de lo irrepresentable. Debe recordarse, en modo ejemplar, que el concepto de límite se perfila como una ficción de la que depende el ámbito de la representación, que los números irracionales son una verdadera aproximación a un límite no alcanzable, que tiempos imaginarios derivan de precisas ecuaciones matemáticas ${ }^{14}$. En fin, que en la ciencia todo se reduce a conjeturas y refutaciones, y las teorías comparten el estatuto mítico al ser imágenes que están y van más allá de su demostración y comprobación.

Las ciencias, entonces, no son monolíticas, sino que actúan como un modo de monolitismo que tiende a anula cualquier posibilidad, remota o no, de verdades transculturales ${ }^{15}$ (y de carácter moral y mental humano universal), noción que tiende a ser despreciada en el espectro de la cultura occidental, entendida como fuerza global irrefrenable y despiadada que borra todo aquello que se le interponga. La ciencia, en el nivel epistémico y metodológico de la abstracción, intenta ocultar el nivel metafísico y ontológico de la realidad, sin éxito, llevando a cabo, en muchas ocasiones, abstracciones e invenciones metodológicas prácticamente "ficcionales» a partir de la imaginación lógica. En el pensamiento científico es habitual la tendencia a descartar las narraciones milagrosas, sobrenaturales, aunque a aceptar mitos seculares, y estereotipados, como los vinculados a las superioridades implícitas de las propias ciencias, o biológico-raciales.

La existencia, entendemos, es indefinidamente plural, y existen muchas clases y maneras de existir; esto es, las cosas existen de variados modos. La verdad es algo social, y está basada en el consenso entre los co-participantes en una objetividad de perspectivas. Está limitada, eso sí, por el contexto al que pertenece, siendo este transitorio, fugaz, efímero. El conocimiento científico y las verdades científicas no dejan de ser irrevocablemente hipotéticas: la verdad o verdades de una hipótesis es una verdad potencial o condicional (como una conjetura). Por otro lado, el método científico de investigación de la naturaleza suele ser limitado en el rango de aplicabilidad. No obstante, escribir una novela, viajar, contemplar el cielo o enamorarse,

${ }^{14}$ Véase Zellini, 1991, pp. 50-51, y Paniker, 1961, esp. pp. 208-209.

${ }_{15}$ Para etnólogos y folcloristas el valor positivo del mito reside en que registra la historia cultural del hombre y señala modelos de pensamiento, de motivación y de conducta transculturales. Véase, por ejemplo, Bidney, 1971, pp. 3-24, esp. p. 22; 1953, pp. 325-326 y 694695; y Schrempp \& Hansen, 2002, esp. pp. 49 y 51. 
no dejan de ser, de algún modo, aspectos sociales que incluyen, también de cierta manera, manipulación, observación y aplicación, y parecen proporcionar «hipótesis» también probadas o probables.

\section{NEWTON, DARWIN Y EL UNIVERSO}

La ciencia moderna mantuvo algunos de sus basamentos, de modo implícito, en la fundamental jerarquía de la realidad platónica, según la cual una naturaleza material diversa y cambiante, se veía obediente a leyes y principios que trascendían los fenómenos que esas leyes gobernaban. La ciencia posee, no obstante, sus propios mitos en forma de paradigmas, que determinan lo que es y lo que no es reconocido como un hecho, como es el caso de la noción del mundo mecánico newtoniano, que fue invalidado con el advenimiento de la física cuántica, el darwinismo, aún dominante en biología, en tanto descalificado a través de la teoría del diseño inteligente, y el principio copernicano, cuyas insuperables dificultades en relación a la formación de estrellas y galaxias lo instalan en el reino de lo mítico.

La ciencia moderna (recuérdese, Bacon, Descartes, Newton, Darwin, Comte), crea herramientas para sojuzgar a la naturaleza, para superar la resistencia del mundo ante la pretensión humana de poder. De un modo general, sin embargo, mitos y teorías (fundamentos lingüísticos de los modelos), no dejan de ser, formalmente, lo mismo. Ambos son explicaciones con un grupo limitado de datos, y son "mitos» acerca de nuestro sitio en el mundo. Aunque las teorías científicas se corroboran, incluyéndose en un mecanismo, dejando de parecer mitos, tal proceso no es diferente al de la conformación de rituales que incluyen implícitamente mitos. Con la ciencia moderna, las antiguas creencias explícitas fueron sustituidas por otras que, o no lo parecían, o se conservaron, pero inconscientemente; «creencias» como las mencionadas gravitación universal o la selección natural ${ }^{16}$.

El mundo mecanicista newtoniano señalaba que lo que existe es materia desnuda, partes de la cual interactúan a través de fuerzas de atracción o repulsión, de modo que el movimiento del conjunto es determinado por la disposición de las partes. Este concepto de materia desnuda es la noción de res extensa cartesiana. Sin embargo, todas las cualidades son subjetivas y, en consecuencia, los objetos externos no son de hecho percibidos en realidad. Tal concepto ha sido degradado al estatus de abstracción ${ }^{17}$. A pesar de su invalidez filosófica, el éxito del paradigma

${ }^{16}$ Aunque se pueden ofrecer pruebas de las creencias evolutivas a través de documentos del pasado, fósiles o experimentos de campo y en el laboratorio, no se hace más que exhibir nuestros criterios particulares de credibilidad. Véase sobre este tema, Salthe, 1993, pp. 95-116, esp. pp. 97-98 y 102-103; Davis, 1965, esp. pp. 19-23; y Campbell, 1921, esp. pp. 52-55.

${ }^{17}$ Véase al respecto, Smith, 2010, esp. pp. 3-4. 
newtoniano ha sido notable hasta que su invencibilidad fue derrotada por la mecánica cuántica, que señala que el conjunto, el todo, no es de hecho reducible a sus partes, siendo ellas finitas o infinitesimales. No es posible, en términos generales, predecir el exacto valor de algo observable; esto es, la noción de "probabilidad» se instala de modo totalmente "sugerente».

El concepto de gravedad newtoniano fue elaborado, no se olvide, a partir de los estudios hechos sobre las simpatías y antipatías de la filosofía hermética y de la alquimia. Newton, de hecho, integra la filosofía mecanicista y la tradición y sabiduría secreta pitagórica.

El darwinismo, por su parte, no es en verdad una teoría científica, sino un postulado ideológico: Darwin concibió la evolución como un proceso gradual que incluía formas intermedias incontables que todavía deben ser halladas. La idea de que la naturaleza produce pequeñas mutaciones que pasan, vía genética es, de hecho, una tautología, vacía de contenido científico. La precisión de las estructuras moleculares anuncia muchos problemas al concepto darwiniano de la evolución ${ }^{18}$. La teoría del diseño inteligente, una disciplina matemática, concluye que ningún proceso compuesto de elección o azar y necesidad, puede dar lugar a una complejidad irreducible, lo que descalifica la visión darwiniana. La selección natural y el darwinismo han conformado un nexo de mitos asociados, creencias que intentan explicar quiénes somos, qué hacemos en el planeta y de dónde procedemos. Las características de los mitos (funcionalmente completos, susceptibilidad de ser totalmente dramatizados y descriptibles en detalles sutiles), se observan en las creencias darwinianas. La teoría de la selección natural, como otras, posee, en consecuencia, una estructura general semejante a la de un mito.

De la selección natural, en el marco del darwinismo, se llegó a hacer un principio trascendental. Se conformó como la fuente primaria de la moralidad y el progreso humano, en actitud cercana a la de una nueva religiosidad (particularmente el humanismo evolutivo) y a peligrosos ideales del tipo del darwinismo Político. Uno de sus presupuestos, esencialmente la aparente uniformidad de la selección natural, puede modificarse (por la deriva y la neutralidad) y afectar los cambios evolutivos, que se hacen así más o menos impredecibles ${ }^{19}$. La teoría de la evolución no puede explicar detalles sobre nuestro origen como humanos ni sobre muchas de nuestras presentes peculiaridades.

${ }^{18}$ Sobre este tema deben revisarse Behe, 1996, esp. pp. 70-75; Johnson, 1996, esp. pp. 4851 y ss.; Smith, 2010, esp. pp. 8-13 y ss; y Stewart, 1989, esp. pp. 12-30.

${ }^{19}$ En el deseo de seguridad plena puede radicar, en parte, la toma de posiciones oficiales, canónicas y hasta dogmáticas, frente el mito, de algunas premisas de la primera filosofía, de la historia y de la ciencia. El pasado, muerto y finiquitado, no puede ser alterado, mientras que el presente es pesaroso y el futuro oscuro, informe, misterioso y, por ende, tenebroso. Véase al respecto, Elton, 1969, esp. pp. 78-79; Barnett, 2000, esp. pp. 52, 55 y 86, y Salthe, 1993, esp. pp. 96-97. 
El naturalismo biológico, por su lado, que hace firmes comparaciones con el mundo animal, traspasándolas a la biología humana y sirviendo como modelo explicativo de nuestra conducta moral y de nuestros comportamientos sociales (incluyendo la violencia antisocial), se presenta como un producto científico, aunque muchos de sus presupuestos se fundamentan en la tradición de los bestiarios medievales. La suposición de que biológica y evolutivamente el ser humano está forzado, instintivamente, como parece mostrar la conducta de ciertos animales, especialmente primates, a desplegar ciertos comportamientos, no deja de ser una mítica suposición engalanada de cientificismo. La historia de la prehistoria de la humanidad está repleta de melodramas, con trogloditas luchando entre sí, con otros grupos, o por sus «mujeres», debido a un condicionante instintivo, genético, propio de la naturaleza animal y, por tanto, también humana.

El actual concepto de Universo, de indudable interés científico, no carece de concepciones seminales (que Einstein denominó como libres creaciones del espíritu humano), cuyas implicaciones filosóficas no son reconocidas en el proceso científico. Como medio de conocimiento, en tal sentido, la ciencia no es autónoma, salvo en ámbito de lo pragmático. El Universo físico no es una realidad descubierta, sino construida, a través del modus operandi de la física, que es una estructura matemática definida en términos operativos ${ }^{20}$. Además de su significación operativa, el formalismo matemático tiene también una significación ontológica.

La más moderna física señala que creamos nuestra realidad al medirla, incluso la mecánica cuántica, tan posibilista. Sin embargo, el hecho de no medir tales posibilidades no significa, necesariamente, la inexistencia de tales realidades, aunque "existan» cuando se materializan en sus mediciones. El famoso teorema matemático de J.S. Bell, de la interconectividad de todas las cosas, demuestra que las polaridades contrastantes responden a una unidad sustancial, sin que se pueda explicar la reversión de polaridades de las partículas cuando se alejan entre sí21. El Universo físico, el concebido por los físicos, no se puede separar de las intervenciones

${ }^{20}$ Ciertos axiomas matemáticos como el que afirma que la línea recta es la distancia más corta entre dos puntos o que las paralelas nunca se encuentran, no son proposiciones probadas, sino dadas de modo auto evidente. Es necesario iniciar un sistema lógico-matemático con algo que no está probado. De tal manera, la matemática, como la ciencia en general, es un producto, en crecimiento continuo, de razón e intuición humanas. La intuición matemática está presente para «adivinar» relaciones y armonías escondidas, como les ha ocurrido a muchos matemáticos. No obstante, la ciencia en la sociedad moderna es algo semejante a una institución, en la que predomina cada vez más la privatización de la innovación como propiedad intelectual. En tal sentido, la "ciencia» puede llegar a ser, como las religiones, un conjunto de instituciones y rituales más o menos fosilizados. Véase O’ Hear, 1989, pp. 78-84 y Barnett, 2000, esp. p. 162.

${ }^{21}$ Sobre estos apuntes debe revisarse Fuller, 1997, esp. pp. 7-8. Acerca de la complejidad de las interrelaciones entre los distintos elementos del mundo, y sobre el probabilismo de la física cuántica, son relevantes Fernández Rañada, 2009, esp. pp. 99-107, y concretamente, p. 104, así como Valverde, 1980, pp. 35-46 y ss. 
efectuadas por los propios físicos, lo que implica que tratan con un Universo participatorio. La ruptura de un sistema físico en partes se produce por una intervención empírica por la que las partes se especifican. Porque la medida de algo observable tiene un efecto no controlable sobre el conjunto, es por ello por lo que el sistema no puede concebirse como una suma de partes bien definidas. Así, la noción de mecanismo universal de Galileo, confirmada por los descubrimientos de Newton y de sus sucesores, parece ya insostenible.

Las leyes de la física, en sus niveles subatómico y molecular y orgánico, parecen exigir una unidad óntica del Universo y un planteamiento monista de lo existente, una suerte de visión holística semejante a la dimensión ontosimbólica de lo míti$\mathrm{CO}^{22}$. La causación universal incluye acontecimientos azarosos, sucesos probabilísticos y causalidades imprevisibles que no pueden obviarse.

Pareciera posible aprehender el Universo de forma biológica, en función de la idea de que nuestro cerebro interpreta los datos que le suministran nuestros receptores sensoriales para elaborar un modelo del mundo. La idea de modelo es adaptada de la física cuántica, la que supone que un sistema (mundo) no tiene una sola versión, sino muchas, una verdadera trama de patrones estructurales y explicativos. Uno de los modelos explicativos sería, en tal sentido, la imaginación mítico-fantasiosa.

\section{CONCLUSIÓN}

Si bien los mitos plantean el Universo en términos de flujos de energía vital, también la física más actual habla del Cosmos en términos paralelos y semejantes (flujos de ondas, cuerdas vibratorias, por ejemplo). Tanto ciencia como mitología se basan en, podría decirse, postulados y supuestos (materialismo y objetivismo realista la primera, y animismo o panpsiquismo ${ }^{23}$ y subjetivismo la segunda), que pueden concebirse como complementarios: la ciencia "resuelve» problemas corporales, y los mitos solucionan o disuelven aquellos inconvenientes psicológicos del alma humana.

El conocimiento científico, por lo tanto, ni es universal ni absoluto, sino con limitaciones y provisional. A causa de que la inducción no puede traducirse en leyes generales, y a causa de que el conocimiento científico es un producto de las estructuras interpretativas humanas, que son, ellas mismas, variables, relativas y

${ }^{22}$ Sobre esto es pertinente la lectura de Puente Ojea, 2007, esp. pp. 17 y 258.

${ }^{23}$ Véase Laszlo, 1977, esp. pp. 15-18 y ss. También puede revisarse Coca (ed.), 2008, esp. p. 42. Cuando hablamos de animismo se implica que el mundo no es mecánico, sino animado de espíritus o genios, energías psíquicas y fuerzas de carácter subjetivo, lo que supone establecer una visión de conjunto en la que todo se enlaza. 
creativamente empleadas (desde la imaginación mítico-simbólica), las verdades de la ciencia no pueden ser, en consecuencia, inequívocamente objetivas. Estas particularidades validan la tesis kantiana de que la naturaleza descrita por la física no es la naturaleza misma sino la relación del hombre con la naturaleza; por tanto, la naturaleza expuesta a las formas de cuestionar del propio ser humano.

\section{REFERENCIAS BIBLIOGRÁFICAS}

Abdalla, M. (2010). La crisis latente del darwinismo. Murcia: Cauac/Crimentales.

Aristóteles (1988). Tratados de Lógica (Órganon). 2 vols. Madrid: Gredos.

Ayala Blanco, L. A. (2004). El silencio de los dioses. México, D. F.: Sexto Piso.

Barnett, A. (2000). Science. Myth or Magic? St. Leonards: Allen \& Unwin.

Behe, M. (1996). Darwin's Black Box. Nueva York: The Free Press.

Bermejo Barrera, J. C. (1994). Entre Historia y Filosofía. Madrid: Akal.

Bidney, D. (1953). Theoretical Anthropology. Nueva York: Columbia University Press.

Bidney, D. (1971). Myth, Symbolism, and Truth. En T. A. Sebeok (ed.), Myth: A Symposium (pp. 3-24). Bloomington: Indiana University Press.

Campbell, J. (1921). What is science? Londres: Methuen.

Chaparro, A. \& Schumacher, Ch. (2003). Racionalidad y discurso mítico. Bogotá: UR edic.

Coca, J. R. (ed.) (2008). Las posibilidades de lo imaginario. Barcelona: edit. del Serbal.

Davis, M. (1965). The undecidable. Nueva York: Raven Press.

Elton G. R. (1969). The Practice of History. Londres: Fontana.

Fernández Rañada, A. (2009). Los científicos y Dios. Madrid: Trotta.

Fuller, S. (1997). Science. Chicago: Open University Press. 
Gellner, E. (1975). The Legitimation of Belief. Cambridge: Cambridge University Press.

Grassi, E. (2003). El poder de la fantasía. Observaciones sobre la historia del pensamiento occidental. Barcelona: Anthropos.

Griffin, D. (1984). Animal Thinking. Cambridge: Harvard University Press.

Gross, A. G. (1990). The Rhetoric of Science. Cambridge, Mass.: Harvard University Press.

Harpur, P. (2010). El fuego secreto de los filósofos. Girona: Atalanta.

Hesse, M. \& Arbib, M. A. (1987). The Construction of Reality. Cambridge: Cambridge University Press.

Hofstadter, D. R. (1979). Godel, Escher, Bach: an eternal golden braid. Nueva York: Basic Books.

Hübner, K. (1981). Wie irrational sind Mythen und GötterB. En H. P. Duerr (comp.), Der Wissebschaftler und das Irrationale, 2 vols. (vol. 2, pp. 11-36). Frankfurt: W. Kolhhammer $\mathrm{GmbH}$.

Hübner, K. (1984). Warum gibt es ein wissenschaftliches ZeitalterB. Hamburgo: Männerschwarm.

Hübner, K. (1996). La verdad del mito. México, D.F.: Siglo XXI.

Johnson, P. (1996). Darwin On Trial. Intervasity Press: Downers Grove, Illinois.

Kolakowski, P., Spaemann, R. \& Löw, R. (comps.). (1986). Moderne oder PostmoderneB zur Signatur des gegen wärtigen Zeitalters. Weinheim: Wiley-VCH.

Kuhn, T. S. (1979). La función del dogma en la investigación científica. Valencia: Universitat de Valencia.

Laszlo, E. (1977). El Cosmos creativo. Barcelona: Kairós.

Losev, A. F. (1998). Dialéctica del mito. Bogotá: Universidad Nacional de Colombia. 
Maxwell, N. (1984). From Knowledge to Wisdom. A Revolution in the Aims and Methods of Science. Londres: Blackwell Publs.

Midgley, M. (2011). The Myths We Live By. Londres: Routledge.

O' Hear, A. (1989). Introduction to the Philosophy of Science. Oxford: Clarendon Press.

Paniker, R. (1961). Ontonomía de la ciencia. Madrid: Gredos.

Páramo, G. (1989). Lógica de los mitos: Lógica paraconsistente. Una alternativa en la discusión sobre la lógica de los mitos. Ideas y Valores, 79, pp. 27-67.

Páramo, G. (1997). Relación explorable e investigable entre mitos y matemáticas. Bogotá: IV Congreso de Investigación. Pontificia Universidad Javeriana, tomo I, pp. 25-32.

Popper, K. (1974). Conjectures and Refutations: The Growth of Scientific Knowledge. Londres: Routledge \& Kegan, P.

Puente Ojea, G. (2007). Vivir en la realidad. Sobre mitos, dogmas e ideologías. Madrid: Siglo XXI.

Rodin, P. (1957). Primitive man as Philosopher. Nueva York: Dover.

Salthe, S. M. (1993). La ciencia como base de una nueva comprensión de lo mitológico. Ponencia del X Seminario Internacional de Estudios Filosóficos, titulado "La Biología entre la Mitología y la Filosofía», CEFPSULT, 1991, revista Ludus Vitalis, 1(1), pp. 95-116.

Schrempp, G. \& Hansen, W. (2002). Myth. A New Symposium. Bloomington: Indiana University Press.

Segal, R. A. (2004). Myth. A Very Short Introduction. Oxford: Oxford University Press.

Selleri, F. (1986). El debate de la teoría cuántica. Madrid: Alianza.

Smith, W. (2010). Science \& Myth. What We Are Never Told. San Rafael: Angelica Press / Sophia Perennis. 
Stewart, R. C. (1989). Shattering the Sacred Myths. Nueva York: Evolutionary Metaphysics.

Stock, G. (2002). Redesigning Humans. Londres: Profile Books.

Tarnas, R. (1991). The Passion of the Western Mind. Nueva York: Ballantine BooksRandom House. (Trad. Esp. 2016. La pasión de la mente occidental. Girona: Atalanta).

Valverde, J. M. (1980). Vida y muerte de las ideas: pequeña historia del pensamiento occidental. Barcelona: Planeta.

Waddington, C. H. (1941). The Scientific Attitude. Harmondsworth: Penguin Books.

Wittgenstein, L. (1987). Tractatus Lógico-philosophicus. Madrid: Alianza.

Zellini, P. (1991). Breve historia del infinito. Madrid: Siruela. 